\title{
The factors influencing the growth and feeding of hatchery- raised Japanese flounder juveniles under various designs of experimental mass releases in the field
}

\author{
YOSUKE TANAKA ${ }^{1 *}$, OSAMU TOMINAGA ${ }^{2}$, TATSUO TSUSAKI ${ }^{3}$ AND MASARU TANAKA $^{1}$ \\ ${ }^{1}$ Graduate School of Agriculture, Kyoto University, Kitashirakawa, Kyoto 606-8502 (yosuket@kais.kyoto-u.ac.jp), \\ Japan, ${ }^{2}$ Faculty of Bioresouces, Fukui Prefectural University, Obama Fukui 917-0003, Japan, ${ }^{3}$ Miyazu Station, \\ Japan Sea Farming Association, Miyazu, Kyoto 626-0063, Japan
}

KEY WORDS: $\begin{aligned} & \text { stock enhancement, mass release, Japanese flounder, field experiment, growth, } \\ & \text { feeding }\end{aligned}$

\section{INTORODUCTION}

Japanese flounder Paralichthys olivaceus is an important species in commercial fisheries and aquaculture in Japan. It has also been the most important model species of stock enhancement for marine fishes. Mass releases of artificially-raised Japanese flounder juveniles have been conducted in the coastal areas almost all over Japan since the mid1980 s, the total number of fishes exceeding twenty four million per year in recent years.

Both the environmental (e.g. water temperature, food availability) and artificial technical factors (e.g. timing, size and number of release) are very important for the post-release feeding and growth of hatchery-raised Japanese flounder juveniles. The information of these factors influencing the postrelease feeding and growth of flounder juveniles is needed for successful stock enhancement.

In our study, various ideas and designs of mass release of hatchery-raised flounder juveniles were experimentally tested in the field. The purpose of this study is to examine the factors influencing feeding and growth of released flounder juveniles using the field experiment and preliminarily discuss mechanisms of the post-release feeding, growth and survival of flounder juveniles in an experimental research field.

\section{MATERIALS AND METHODS}

Experimental field, Wada Beach is located in Wakasa Bay, Fukui Prefecture, mid-coastal area of the Sea of Japan. Experimental mass releases were conducted in 1997, 1998, and 2000. Table 1 shows the details of each mass release. All juveniles were marked in otoliths with alizalin complexon to discriminate between the released and wild juveniles. Released juveniles were recaptured by $2.0 \mathrm{~m}$ beam trawl. Mysids (main prey item of Japanese flounder juveniles) were simultaneously sampled at the juvenile sampling with a sledge net $(0.6 \mathrm{~m}$ mouth width). Samples used in analyses were taken from the samples caught more than 7 days later from the release date, because heavy mortality generally occur within the 1st week.

Wet weight of stomach contents of released juveniles was measured. According to Yodo et al. ${ }^{1}$, stomach contents index (SI) was calculated to compare the feeding strength of juveniles in a wide range of sizes. Growth of released juveniles was estimated by otolith microstructure analysis.

Average SI of released juveniles collected 7 days after release and average growth rate $(\mathrm{mm} /$ day) of cited juveniles for 5 days after release were cited as the indexes of feeding and growth. Following 7 environmental and technical factors were used to examine the relationships between two indexes: 1) water temperature at release (WT), 2) cumulative wet weight of mysids after mass release (CWM), 3) catch per unit effort (CPUE) of wild flounder juveniles at release (CPUE-W), 4) CWM /CPUE of wild flounder juveniles at release (CWM/CPUE-W), 5) number of

Table 1 Details of experimental mass releases.

\begin{tabular}{lccc}
\hline Release group & Release date & $\begin{array}{c}\text { Release } \\
\text { size } \\
\text { (mmIL) }\end{array}$ & $\begin{array}{c}\text { Number of fish } \\
\text { released }\end{array}$ \\
\hline 1997 early & May 29, 1997 & 53.5 & 40,000 \\
1997 late & July 2, 1997 & 51.8 & 40,000 \\
1998 large & May 21, 1998 & 60.7 & 50,000 \\
1998 small & May 21, 1998 & 37.1 & 50,000 \\
2000 & June 7, 2000 & 55.7 & 60,000 \\
\hline
\end{tabular}


Table 2 Calculation of the simple correlation coefficient. The data are SI (all), SI without 1997 late-release group, and growth rate among environmental and technical factors.

\begin{tabular}{cccccccc}
\hline & WT & CWM & CPUE-W & CWM/CPUE-W & NUR & CPUE-WR & CWM/NUR \\
\hline SI (all) & -0.807 & 0.625 & -0.146 & 0.679 & -0.136 & -0.285 & 0.550 \\
SI(without 1997 & -0.988 & 0.984 & -0.050 & 0.893 & -0.710 & -0.993 & 0.991 \\
$\begin{array}{c}\text { late group) } \\
\text { Growth rate }\end{array}$ & 0.398 & 0.544 & 0.234 & 0.363 & -0.673 & -0.695 & 0.621 \\
\hline
\end{tabular}

fish released (NUR), 6) CPUE of flounder juveniles including released and wild juveniles one day after release (CPUE-WR) and 7) CWM/number of fish released (CWM/NUR). 1) through 4) are environmental factors, 5) and 6) are technical factors and 7) is the combined factor.

Correlation coefficients between these factors and feeding and growth were calculated. And analysis of variance was applied to these growth rates in order to compare them among each experimental design.

\section{RESULTS}

Average SI demonstrated positive correlations with CWM and CWM/CPUE-W $\quad(r=0.625, \quad 0.679$, respectively), negative correlation with WT ( $r=$ -0.807) (Table 2). However, these correlation coefficients were not significant. Since 1997 laterelease group had shifted their prey from mysids to fish larvae, ${ }^{2}$ we analyzed them after excluding 1997 late-release group. Average SI demonstrated strong positive correlations with CWM, CWM/CPUE-W, and CWM/NUR $(r=0.984,0.893$, and 0.990 , respectively), strong negative correlations with WT and CPUE-WR ( $r=-0.988$ and -0.993 , respectively). These results suggest that feeding of released juveniles depend on the food density and their availability.

Average growth rate also demonstrated a positive correlation with CWM/NUR ( $r=0.621)$, and negative correlations with NUR and CPUE-WR ( $r=-0.672$ and -0.695 , respectively), although these correlation coefficients were not significant.

Although only the growth rate of 1998 large-size release group was significantly lower that of 1997 late group ( $\mathrm{df}=4, F=4.467, p<0.05$ : Bonfferoni test, $p<0.05$ ), significant differences were not found on the whole.

\section{DISCUSSION}

It is clear that water temperature and prey mysids abundance were important factor for feeding of released flounder (Table 2). Growth rate negatively depended on NUR and induced factors by NUR (Table 2). Those suggest that environmental factors influenced their feeding and technical factors influenced their growth. A combined effect of experimental and technical factors (CWM/NUR) influenced both the feeding and growth. These results also suggest that excess amount of release is not necessarily effective. Furthermore, number of fish released must be examined carefully for effective mass release even in the case of high mysids abundance in the nursery because of the importance of relative abundance of mysids.

The reason why significant differences in growth rate were not clearly observed among various experimental designs, may be associated with the mortality of low-growth juveniles and the emigration of high-growth juveniles from the experimental field. It is speculated that food availability and density of juveniles influenced feeding and growth of juveniles which remained in the experimental field, and the environmental and technical factors could determine the mortality and emigration of released juveniles. The emigration of released juveniles should be examined in future study for the effective stock enhancement to understand density-dependent mechanism in more details.

\section{REFERENCES}

1. Yodo T. Kimura S. Feeding habits of large mouth bass Micropterus salmoides in lake Shorenji and Nishinoko, central Japan. Nippon Suisan Gakkaishi 1998; 64(1): 26-38

2. Tanaka $Y$, Tominaga $O$, Tsusaki $T$, Nogami $K$, Fushimi $H$, Tanaka $M$. UJNR experimental release of Japanese flounder at Wada Beach, Wakasa Bay : feeding habits of wild and relesed juveniles. Bull. Natl. Res. Inst. Aquacult., Suppl. 1 1999; 125-133. 